\section{Paying My COVID-19 Dues}

As many of my colleagues know, I recently experienced a "vaccination breakthrough" case and paid my COVID-19 dues with a stay in an intensive care unit in August. While too numerous to name here, I would like to thank all of those from the microscopy and microanalysis communities who provided support through their thoughts and prayers during that difficult time. While in the ICU and in recovery, I realized how important the MSA and MAS friendships I have established over the years are in my life. The support from all of you certainly helped in my recovery.

My stay in the ICU provided me with some unexpected free time, and, not able to do much more than stare at the ceiling, I began to think about the important role that microscopy and microanalysis have played in combating the COVID-19 pandemic. From the early cryo-EM 3D reconstructions of the coronavirus presented on the news media to raise public awareness, to the development of vaccines as detailed in the M\&M 2021 Plenary presentation by Jason McLellan, imaging has been at the forefront of understanding COVID-19 structure and function. Many sessions at the meeting including Imaging, Microscopy, and Micro/Nano-Analysis of Pharmaceutical, Biopharmaceutical, and Medical Health Products - Research, Development, Analysis, Regulation, and Commercialization; Cryo-EM in Drug Discovery; and Challenges and Advances in Electron Microscopy Research and Diagnosis of Diseases in Humans, Plants and Animals also addressed topics relevant to studying COVID-19 and other diseases.

Many MSA Focused Interest Groups (FIG), including 3D EM in the Biological Sciences; Cryopreparation; Diagnostic and Biomedical Microscopy; and the Pharmaceuticals group, also use a range of imaging techniques to study viruses as well as other microbes and diseases. If your research and interests align with any of these or other MSA FIGs, please consider joining and contributing to the important research being performed in these groups. A full list of FIGs can be found on the MSA website at Communities | Focused Interest Groups (https://www.microscopy.org/communities/ fig.cfm). I can personally vouch for the personal and professional benefits that being a member of these communities provides, and I encourage all to join the group(s) that fit your interests and research.

Robert L. Price

Editor-in-Chief

Publication Objective: to provide information of interest to microscopists.

Microscopy Today is a controlled-circulation trade magazine owned by the Microscopy Society of America that is published six times a year in the odd months. Editorial coverage spans all microscopy techniques including light microscopy, scanning probe microscopy, electron microscopy, ion-beam techniques, and the wide range of microanalytical methods. Readers and authors come from both the life sciences and the physical sciences. The typical length of an article is about 2,000 words plus figures and tables; feature articles are longer. Interested authors should consult "Instructions for Contributors" on the Microscopy Today website: www.microscopy-today.com.

\section{ISSN 1551-9295}

\section{Disclaimer}

The Microscopy Society of America and the editors cannot be held responsible for opinions, errors, or for any consequences arising from the use of information contained in Microscopy Today. The appearance of advertising in Microscopy Today does not constitute an endorsement or approval by the Microscopy Society of America of any claims or information found in the advertisements. By submitting a manuscript to Microscopy Today, the author warrants that the article is original or that the author has written permission to use copyrighted material published elsewhere. While the contents of this magazine are believed to be accurate at press time, neither the Microscopy Society of America, the editors, nor the authors can accept legal responsibility for errors or omissions.

(C) The Author(s), 2021. Published by Cambridge University Press on behalf of the Microscopy Society of America. All rights reserved.

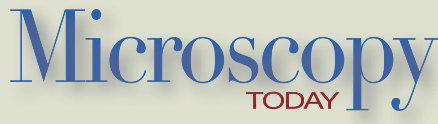

\section{Editorial Staff}

Robert L. Price, Editor-in-Chief

bob.price@uscmed.sc.edu

(803) 216-3824

Gennifer Levey, Production Manager glevey@meridianartpro.com

(212) 780-0315

Beverly Maleeff, Administrative Editor bev@alumni.psu.edu

Charles E. Lyman, Senior Editor

charles.lyman@lehigh.edu

Phil Oshel, Senior Editor

oshel1pe@cmich.edu

Stephen Carmichael, Columnist

carmichael.stephen@mayo.edu

John Shields, Columnist

johnshields59@gmail.com

Cameron Varano, Pioneers Editor

cvarano@psu.edu

Richard Edelmann, Education Editor

edelmare@miamioh.edu

Deb Kelly, Microscopy 101 Editor

debkelly@psu.edu

Rich Fiore, Product and Industry News Editor

rich@scifisalesinc.com

Rich Martens, Calendar Editor

rmartens@ues.com

Nikolaus Cordes, Digital Content Editor

nikolaus.cordes@inl.gov

Thomas Kelly, Chief Innovation Judge

thomas.kelly@ametek.com

Robert Simmons, Chief Micrograph Judge

robert.simmons@briarwillow.com

Advertising Sales

M.J. Mrvica Associates, Inc.

2 West Taunton Avenue, Berlin, NJ 08009

mjmrvica@mrvica.com

(856) 768-9360

Kelly Miller, Account Manager

kmiller@mrvica.com

Magazine website:

http://www.microscopy-today.com

Free subscriptions are available.

Publisher

Cambridge University Press

One Liberty Plaza, 20th Floor

New York, New York 10006

(212) $337-5000$

Circulation: 18,000

Editorial Board

Nasim Alem, Penn State University Arlan Benscoter, Lehigh University John Bozzola, Southern Illinois University

Peter Crozier, Arizona State University

Vinayak Dravid, Northwestern University

David Grubb, Cornell University

Bryan Huey, University of Connecticut

Heather Lowers, U.S. Geological Survey

John Mackenzie, North Carolina State Univ.

Paul Maddox, U. of North Carolina-Chapel Hill

Ania Majewska, U. Rochester Med School

Joseph Michael, Sandia National Labs

Caroline Miller, Indiana University

Brian M. Patterson, Los Alamos National Lab

John Reffner, John Jay College, SUNY

Ian Robertson, University of Wisconsin

Phillip Russell, Appalachian State University

Bradley Thiel, SUNY Polytechnic Institute

Simon Watkins, University of Pittsburgh

Cynthia Zeissler, Nat. Inst. of Stds. and Tech. (NIST) 